\title{
Optimal temperature and $\mathrm{Mn}$ content for enhancing optical properties and inducing room temperature ferromagnetism of $\mathrm{Mn}$ doped $\ln _{2} \mathrm{O}_{3}$ nanocubes
}

\author{
M. A. Awad ${ }^{1} \cdot$ Mohamed Rabia ${ }^{2,3}$
}

Received: 27 December 2021 / Accepted: 25 January 2022 / Published online: 22 February 2022

(c) The Author(s) 2022

\begin{abstract}
In this strategy, chemical vapor deposition technique is utilized to synthesize undoped and $\mathrm{Mn}$ doped $\operatorname{In}_{2} \mathrm{O}_{3}$ nanostructures. Temperature effects on oxygen content, doping level and the associated morphological, structural, optical and magnetic properties have been investigated. The surface morphology examinations showed the ability of manganese ions to catalyze the nanoflakes of undoped $\operatorname{In}_{2} \mathrm{O}_{3}$ to grow into nanocubes. An appropriate proposal for the growth mechanism has been elucidated. X-ray diffraction proved that Mn doping enhanced the growth of $\operatorname{In}_{2} \mathrm{O}_{3}$ along different crystallographic planes with preferred growth of the (222) plane. The strain and dislocation density were decreased while grain sizes were increased with increasing $\mathrm{Mn}$ content. The optical analysis showed reduction in transmission that was related to oxygen vacancies in undoped $\operatorname{In}_{2} \mathrm{O}_{3}$ and phase separation in doped samples. The optical band gap values were decreased from 3.82 to $3.71 \mathrm{eV}$ with increasing $\mathrm{Mn}$ content whereas the refractive index values were increased. The magnetic response elucidated the optimal temperature and $\mathrm{Mn}$ content for inducing the room temperature ferromagnetism.
\end{abstract}

Keywords Mn doped $\operatorname{In}_{2} \mathrm{O}_{3} \cdot \mathrm{CVD} \cdot$ Nanoflakes $\cdot$ Nanocubes $\cdot$ Oxygen vacancies $\cdot$ Ferromagnetism $\cdot$ Optical properties

\section{Introduction}

In recent years, the researcher's interest in synthesizing diluted magnetic semiconductors (DMS) have been increased. DMS are new class of materials that join the properties of both magnetic materials and semiconductors ones. The initial studies on tri-element diluted semiconductors showed limitation due to their low Curie temperature and high raw-material cost. The introduction of transition elements into a compatible semiconductor recently became the most prevailing setting for the fabrication of room temperature ferromagnetism (RTFM) [1]. As one of these systems,

M. A. Awad

arwamadeha@yahoo.com

1 Physics Department, Faculty of Science, Sohag University, Sohâg 82524, Egypt

2 Nanophotonics and Applications (NPA) Lab, Physics Department, Faculty of Science, Beni-Suef University, Beni Suef 62514, Egypt

3 Polymer Research Laboratory, Chemistry Department, Faculty of Science, Beni-Suef University, Beni Suef 62514, Egypt
Mn doped $\operatorname{In}_{2} \mathrm{O}_{3}$ have been attracted the researcher's interest, because Mn brings new physics by the introduction of localized spins [2]. Several techniques have been developed in order to obtain controllable shape, structure and dimension of DMS [3]. Unluckily, the low solubility of transition elements form clusters and heterogeneous regions that hinder the realization of RTFM [4]. On contrary, the chemical vapor deposition technique (CVD) is marked by the preparation of homogeneous alloys with high quality and performance [5,6]. Also it allows the direct synthesis utilizing pure oxides, metals or mixed oxides/metals as precursors avoiding reactions of poisonous and potentially expensive starting materials. Via controlling the parameters of synthesizes (such as the amount of doping materials, growth temperature, percentage and type of reactive and carrier gases, thickness and type of the catalyst, type and location of the substrates) different types of morphologies can be precisely obtained [7-9].

The origin of RTFM of Mn doped $\operatorname{In}_{2} \mathrm{O}_{3}$ has been interpreted by various models [10-21]. For instance, the theoretical s-d microscopic model and the green's function theory attributed the RTFM to the surface oxygen vacancies plus the disparity of ionic radii of both dopant and host [22]. 
Fig. 1 The temperature profile of the tube furnace

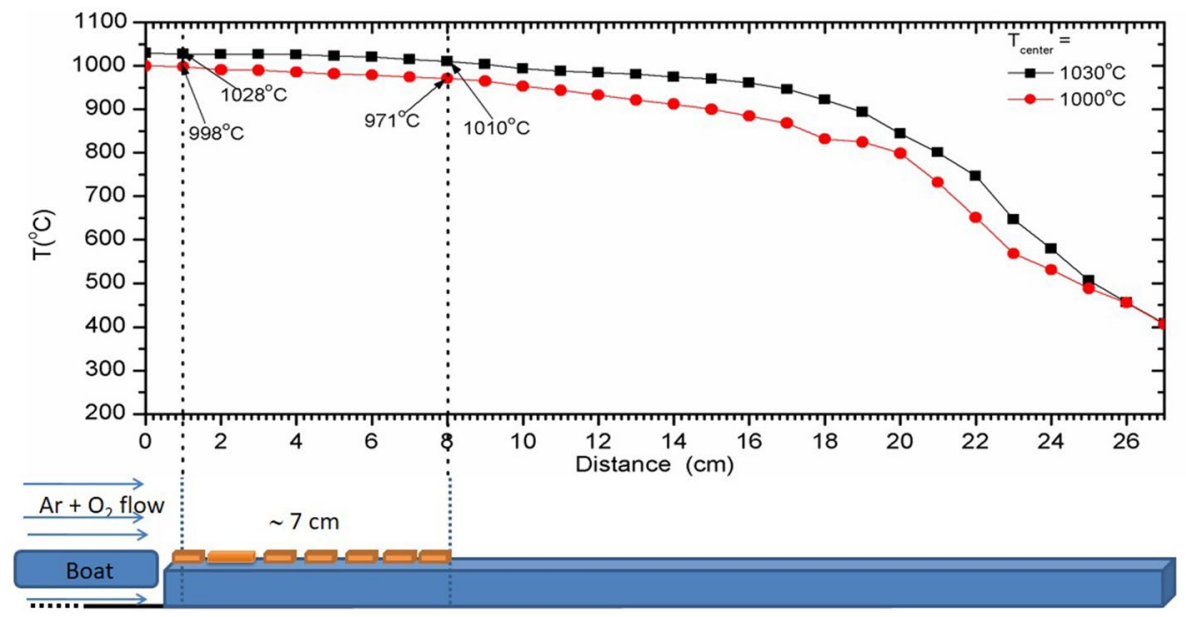

Wang et al. [23] suggested that oxygen vacancies play mediated role in making coupling between Mn ions. Okazaki et al. [24] attributed the room temperature ferromagnetism in $\mathrm{Mn}$ and $\mathrm{Fe}$ co-doped $\mathrm{In}_{2} \mathrm{O}_{3}$ to the coexistence of $\mathrm{Mn}^{2+}$ and $\mathrm{Mn}^{3+}$ ions.

The optical properties of $\operatorname{In}_{2} \mathrm{O}_{3}$ nanostructures have found to be sensitive to Mn doping ratio [25]. Anand et al. [26] reported a red shift in the optical band gap and high photoluminescence intensity up on Mn doping in $\operatorname{In}_{2} \mathrm{O}_{3}$ nanoparticles. Sun et al. [27] found that by tailoring the optical band gap of the prepared $\mathrm{Mn}$ doped $\mathrm{In}_{2} \mathrm{O}_{3}$ thin films, the photoelectrochemical (PEC) activities are promoted and the PEC water splitting efficiency is enhanced. Amiri et al. [28] used the first-principles calculations that are based on the density functional theory, to calculate the optical spectra of $\mathrm{Mn}$ doped $\mathrm{In}_{2} \mathrm{O}_{3}$ in the energy range $0-40 \mathrm{eV}$. They found that the refractive index increased with Mn doping.

The current study aimed to examine the influence of $\mathrm{Mn}$ content on tuning the morphological, optical and magnetic properties of $\mathrm{In}_{2} \mathrm{O}_{3}$ nanostructure using CVD technique. The challenge here lies in determining the range of temperatures and $\mathrm{Mn}$ content that achieve the room temperature ferromagnetism. Also, proving that the synthesis of DMS at relatively high temperature do not disturb the magnetic dipoles. The confirmation of the oxygen deficient for inducing room temperature ferromagnetisms has been also investigated.

\section{Experimental procedures}

Thin films of undoped and $\mathrm{Mn}$ doped $\mathrm{In}_{2} \mathrm{O}_{3}$ nanostructures were synthesized using chemical vapor deposition technique. A horizontal tube furnace of inner diameter $5.5 \mathrm{~cm}$ and length of $100 \mathrm{~cm}$ was used for samples preparation. The deposition were achieved on Au-coated ( 15-20 nm) $\mathrm{Si}$ (100) and quartz substrates that are previously cut into $1 \times 1 \mathrm{~cm}^{2}$ and cleaned via ultrasonic equipment. Mixtures of $\mathrm{In}+\mathrm{In}_{2} \mathrm{O}_{3}$ granules with ratios of 1:1 wt.\% were used as precursor for the $\mathrm{In}_{2} \mathrm{O}_{3}$ nanostructures growth at temperature of $1000{ }^{\circ} \mathrm{C}$. The $\mathrm{Mn}$ doped $\mathrm{In}_{2} \mathrm{O}_{3}$ nanostructures were synthesized using mixtures of $\mathrm{In}+\mathrm{In}_{2} \mathrm{O}_{3}+\mathrm{MnO}_{2}$ granules with ratios of 2:2:1 wt.\% at temperatures of $1000{ }^{\circ} \mathrm{C}(\mathrm{Mn}-1000)$ and $1030{ }^{\circ} \mathrm{C}$ (Mn-1030) (Aldrich chemicals; 99.98\%). The suitable quantities were loaded in an alumina boat at the center of the tubular furnace and heated with a rate of $9^{\circ}$ per minute, while the substrates were located along $15 \mathrm{~cm}$ distance after the boat. Figure 1 shows the temperature gradient through which the tested films are placed. Gas mixture of Ar and $\mathrm{O}_{2}$ was introduced into the system with flow rates of $200 \mathrm{sccm}$ and $15 \mathrm{sccm}$ in series, where argon was allowed to flow from the start of the experiment while oxygen flow was synchronized with the synthesis stage. The time of synthesis was $3 \mathrm{~h}$ for each group after that the furnace was cooled naturally to room temperature. A typical white-yellow precipitate was carefully collected for examination.

The crystal structure was examined using X-ray diffraction (XRD). The patterns were achieved by Bruker D8 ADVANCE diffractometer. The diffractometer utilizes $\mathrm{Cu}-\mathrm{K}_{\alpha}$ radiation of wavelength $\lambda=1.54056 \AA$. The morphology of the prepared thin films was observed by field emission scanning electron microscope (SEM) (model Quanta 250 FEG). The elemental ratios were evaluated by Energy Dispersive Analyses of X-ray (EDAX) unit attached to SEM. The thicknesses were estimated utilizing a Form Talysurf 50 profilometer. The reflectance $(R)$ and transmittance $(T)$ spectra were measured at normal incidence using Jasco V-670 UV-Vis-NIR spectrophotometer over the wavelength range from 200 to $2500 \mathrm{~nm}$. The vibrating sample magnetometer (mode 7410 series VSM, Lake Shore cryotronics, Westerville, OH, USA) was utilized to test the magnetic response of the samples under the application of magnetic field. The measurements were done at room temperature. 


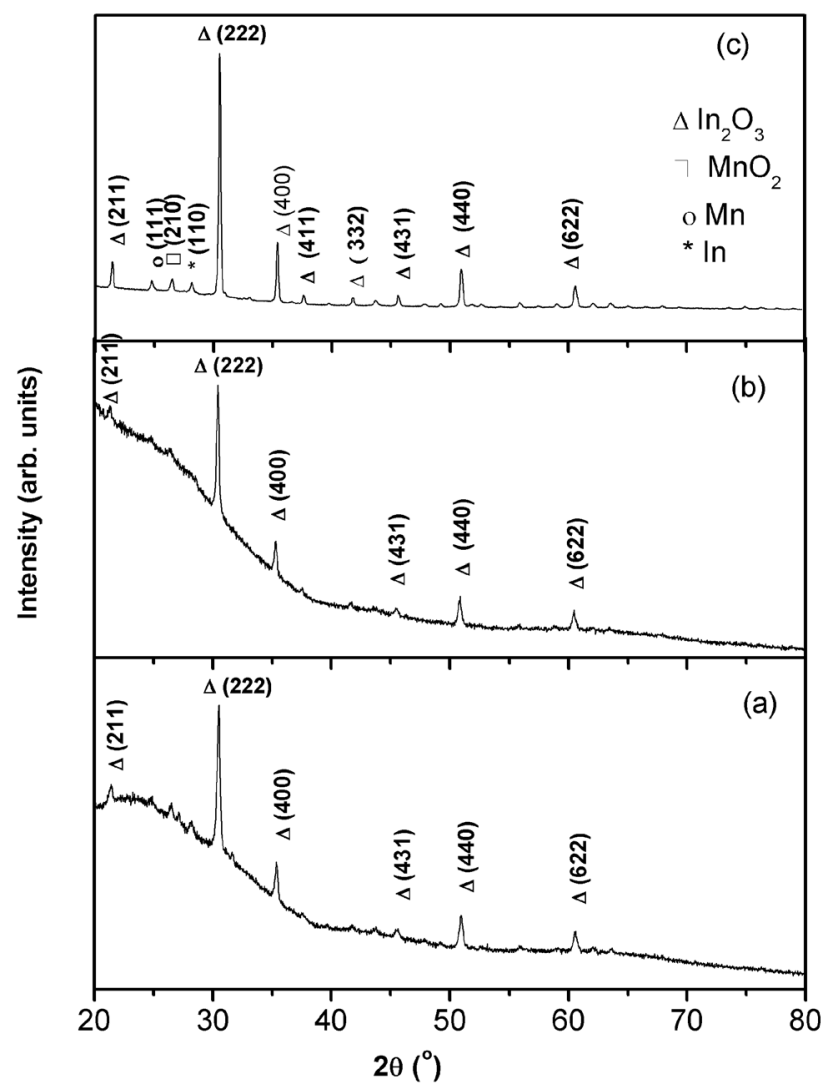

Fig. 2 XRD of a undoped $\operatorname{In}_{2} \mathrm{O}_{3}$, b Mn-1000 and c Mn-1030 thin films

\section{Results and discussion}

\subsection{Structural, morphological and compositional examinations}

The X-ray diffraction patterns of the films are depicted in Fig. 2a-c. Clearly, all diffracted peaks are basically indexed to single phase of cubic $\operatorname{In}_{2} \mathrm{O}_{3}$ (COD: 2310009) with the domination growth of the (222) planes that is more clear in $\mathrm{Mn}-1030$. No prominent change in diffracted peaks of Mn-1000 (Fig. 2b) compared with the undoped $\operatorname{In}_{2} \mathrm{O}_{3}$ (Fig. 2a) that confirms the good solubility of Mn ions within the indium oxide crystal lattice. In addition, there is a possibility that the Mn ions may segregate to the amorphous parts at grain boundaries $[29,30]$. The separate phases of In (COD: 9012377), $\mathrm{Mn}$ (COD: 1539039) and $\mathrm{MnO}_{2}$ (COD: 9011409) appeared in Mn-1030 (Fig. 2c), as a result of exceeding the limit of solubility in $\operatorname{In}_{2} \mathrm{O}_{3}$ crystal lattice. Also, the competitive growth of the overcrowded vapor species in the ambient of the reaction may delay the crystal growth [31]. The small lower shift in the diffracted peaks of $0.3^{\circ}$ in case of $\mathrm{Mn}-1000$ is due to the lattice expansion by the incorporation of $\mathrm{Mn}^{+2}$ ions (ionic radius $0.83 \AA$ ) at the expense of $\mathrm{In}^{+3}$ ions (ionic radius $0.8 \AA$ ) [32]. In case of Mn-1030 (Fig. 2c), the shift in $2 \theta$ does not exceed 0.02 referring to the existence of different oxidation states other than $\mathrm{Mn}^{+2}$ ions in the $\operatorname{In}_{2} \mathrm{O}_{3}$ crystal matrix.

The preferred orientation can be determined by calculating the relative texture coefficient, $\mathrm{TC}(h k l)$, known as Harris analysis [33] given by the equation:

$\operatorname{TC}\left(h_{i} k_{i} l_{i}\right)=\left(\frac{I\left(h_{i} k_{i} l_{i}\right)}{I_{r}\left(h_{i} k_{i} l_{i}\right)}\right)\left(\frac{1}{N} \sum_{i=1}^{N} \frac{I\left(h_{i} k_{i} l_{i}\right)}{I_{r}\left(h_{i} k_{i} l_{i}\right)}\right)^{-1}$

where $I\left(h_{i} k_{i} l_{i}\right)$ refers to the intensity of the diffracted peaks of the sample, $I_{r}\left(h_{i} k_{i} l_{i}\right)$ refers to the intensity of the standard powder sample (COD cards) and $N$ is the number of diffraction peaks. If TC $\left(h_{i} k_{i} l_{i}\right)$ is more than 1 , the plane is said to be preferred oriented. The estimated texture coefficient are presented in Table 1 that indicate the preferred orientation of the plane (222).

The crystallite size $(C)$, dislocation density $(\delta)$ and strain $(\varepsilon)$ are depicted in Table 2 using the equations:

$C=\frac{0.9 \lambda}{\beta \cos \theta_{c}}$

$\delta=\frac{1}{C^{2}}$

$\varepsilon=\frac{\beta \cos \theta}{4}$

where $\beta$ refers to the FWHM and $\lambda$ refers to the wavelength of X-ray. It is noticeable that both strain and dislocation density are decreased while grain sizes are increased with increasing Mn content.

The surface morphology in Fig. 3 shows uniform distribution over the whole film surface. In case of undoped $\operatorname{In}_{2} \mathrm{O}_{3}$, at $1000{ }^{\circ} \mathrm{C}$ (Fig. 3a, b), entangled nanoflakes with terraced nanopyramids are grown perpendicular to the substrate. The research results of Herrera et al. [32] showed the inability of synthesizing thin films of $\operatorname{In}_{2} \mathrm{O}_{3}$ below $1200{ }^{\circ} \mathrm{C}$ using CVD technique. The incorporation of $\mathrm{Mn}$ in the structure catalyzed the nanoflakes to grow into nanocubes (Fig. 3c, d). The same result is reported in ref [34]. The elongated growth of indium oxide cannot be justified due to the small difference in surface energy along different crystallographic planes [32]. Increasing the deposition temperature to $1030{ }^{\circ} \mathrm{C}$ (Fig. 3e, f) stimulated the cubes to grow in a direction perpendicular to substrates. Noteworthy, the growth temperature, the flow rate of the carrier gas, the duration of reaction and the nature of the substrate are number of factors that have great influence on different properties of the product.

An explanation of the growth mechanism of nanostructures thin films can be summarized as following: (i) 
Table 1 X-ray diffraction intensities and relative texture coefficients

Table 2 Precursors, crystallite size $(C)$, dislocation density $(\delta)$ and strain $(\varepsilon)$ of Mn doped $\mathrm{In}_{2} \mathrm{O}_{3}$

\begin{tabular}{|c|c|c|c|c|c|c|c|}
\hline \multirow[t]{2}{*}{$\overline{(h k l)}$} & \multirow[t]{2}{*}{$I_{r}$} & \multicolumn{2}{|c|}{ Pure $\mathrm{In}_{2} \mathrm{O}_{3}$} & \multicolumn{2}{|c|}{ Mn-1000 } & \multicolumn{2}{|c|}{ Mn-1030 } \\
\hline & & $I$ & $\mathrm{TC}(h k l)$ & $I$ & $\mathrm{TC}(h k l)$ & $I$ & $\mathrm{TC}(h k l)$ \\
\hline$\Delta(211)$ & 111 & 98 & 1.15 & 95 & 0.97 & 96 & 1.39 \\
\hline $\mathrm{O}(111)$ & 19 & & & & & 18 & 1.52 \\
\hline$\square(210)$ & 999 & & & & & 49 & 0.08 \\
\hline$*(110)$ & 457 & & & & & 40 & 0.14 \\
\hline$\Delta(222)$ & 1000 & 1000 & 1.31 & 1000 & 1.13 & 1000 & 1.60 \\
\hline$\Delta(400)$ & 293 & 234 & 1.04 & 234 & 0.90 & 235 & 1.29 \\
\hline$\Delta(411)$ & 45 & & & & & 36 & 1.28 \\
\hline$\Delta(332)$ & 35 & & & & & 29 & 1.33 \\
\hline$\Delta(431)$ & 46 & 34 & 0.97 & 33 & 0.81 & 34 & 1.185 \\
\hline$\Delta(440)$ & 375 & 232 & 0.81 & 240 & 0.72 & 152 & 0.65 \\
\hline$\Delta(622)$ & 261 & 145 & 0.73 & 158 & 0.68 & 89 & 0.55 \\
\hline
\end{tabular}

The symbols $\Delta, \mathrm{O}, \square$ and $*$ referee to $\mathrm{In}_{2} \mathrm{O}_{3}, \mathrm{Mn}, \mathrm{MnO}_{2}$ and In phases

\begin{tabular}{lllll}
\hline Sample & Precursors & $\begin{array}{l}\text { Crystallite size } \\
(\mathrm{nm})\end{array}$ & $\begin{array}{l}\text { Dislocation density } \\
\left(\text { lines } / \mathrm{nm}^{2}\right)\end{array}$ & Strain \\
\hline Pure $\mathrm{In}_{2} \mathrm{O}_{3}$ & $\mathrm{In}+\mathrm{In}_{2} \mathrm{O}_{3}(1: 1$ wt. $\%)$ & 30 & $1.1 \times 10^{-3}$ & $1.2 \times 10^{-3}$ \\
Mn-1000 & $\mathrm{In}+\mathrm{In}_{2} \mathrm{O}_{3}+\mathrm{Mn}(2: 2: 1$ wt. $\%)$ & 35 & $8.2 \times 10^{-4}$ & $9.9 \times 10^{-4}$ \\
Mn-1030 & $\mathrm{In}+\mathrm{In}_{2} \mathrm{O}_{3}+\mathrm{Mn}(2: 2: 1$ wt. $\%)$ & 42 & $5.6 \times 10^{-4}$ & $9.3 \times 10^{-4}$ \\
\hline
\end{tabular}
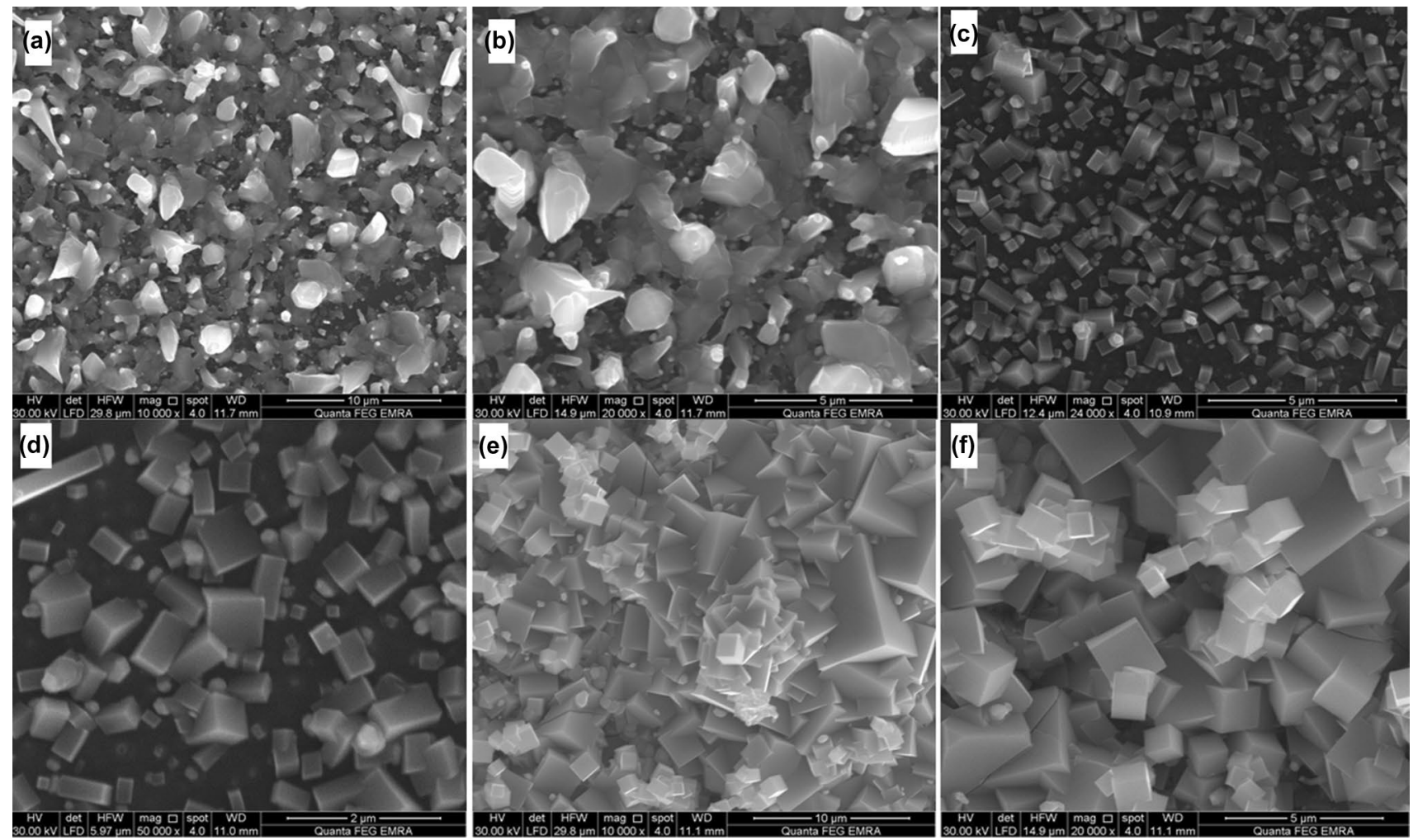

Fig. 3 SEM images with low and high magnifications for $\mathbf{a}, \mathbf{b}$ undoped $\mathrm{In}_{2} \mathrm{O}_{3}, \mathbf{c}, \mathbf{d} \mathrm{Mn}-1000$ and e, f Mn-1030 thin films 
Table 3 Elemental rations (at.\%) and optical band gap $\left(E_{\mathrm{g}}\right)$ of $\mathrm{Mn}$ doped $\mathrm{In}_{2} \mathrm{O}_{3}$

\begin{tabular}{llllll}
\hline Sample & \multicolumn{4}{l}{ Elemental ratios (at.\%) } & \multirow{2}{*}{$E_{\mathrm{g}}(\mathrm{eV})$} \\
\cline { 2 - 5 } & $\mathrm{In}$ & $\mathrm{Mn}$ & $\mathrm{O}$ & Composition & \\
\hline $\mathrm{In}_{2} \mathrm{O}_{3}$ & 42.11 & - & 57.89 & $\mathrm{In}_{2} \mathrm{O}_{2.75}$ & 3.82 \\
$\mathrm{Mn}-1000$ & 40.01 & 4.23 & 54.71 & $\mathrm{In}_{2} \mathrm{Mn}_{0.15} \mathrm{O}_{2.73}$ & 3.77 \\
$\mathrm{Mn}-1030$ & 38.9 & 7.02 & 54.08 & $\mathrm{In}_{2} \mathrm{Mn}_{0.26} \mathrm{O}_{2.78}$ & 3.71 \\
\hline
\end{tabular}

vaporization of solid species (ii) vapor transportation by carrier gases, (iii) species deposition on substrates surfaces, finally (iv) nucleation and growth on different substrates. The utilization of Au catalyst is in order to protect the volatile species from being submerged [35]. With deep insight, one can see random nucleation then nucleation and growth that are governed by the surface energies [36]. In this context, indium and indium oxide are dissociated into various species that are transported by carrier gases to different substrates. The low formation energy of $\mathrm{In}_{2} \mathrm{O}_{3}\left(\Delta_{f} H_{m}^{0}=-925.8 \mathrm{~kJ}\right.$ mole $\left.{ }^{-1}\right)$ facilitated the growth of $\mathrm{In}_{2} \mathrm{O}_{3}$ into nanoflakes then terraced nanopyramid. On the other hand, the high formation energy of $\mathrm{MnO}_{2}$ $\left(\Delta_{f} H_{m}^{0}=42 \pm 1.6 \mathrm{~kJ} \mathrm{~mole}^{-1}\right)$ helped the existence of $\mathrm{Mn}$ ions as doping element instead of being as separate phase [37]. The substitute of $\mathrm{In}^{+3}$ by $\mathrm{Mn}^{+2}$ creates charge imbalance that may be returned by somehow. At $1000{ }^{\circ} \mathrm{C}$, the difference of electro negativities of In (1.78) and Mn (1.55) ions is not sufficient to restore the charge balance. Increasing temperature to $1030{ }^{\circ} \mathrm{C}$ will increase the charge motility, hence approaching charge symmetry [32], see EDAX results in Table 3. As a result of solubility limit $\mathrm{Mn}$ ions in $\mathrm{In}_{2} \mathrm{O}_{3}$ crystal lattice, a separate phase of $\mathrm{MnO}_{2}$ are created at temperature of $1030{ }^{\circ} \mathrm{C}$.

The EDAX analysis is used to quantify the elemental ratios in the composition. Generally, the data recorded in Table 3 shows over stoichiometric of indium due to oxygen deficient in all the synthesized films, in consistent with that previously reported data $[38,39]$. The checkup on Mn-1000 and $\mathrm{Mn}-1030$ indicated the presence of $\mathrm{Mn}$ atoms with approximate ratios of 4.23 at.\% and 7.02 at.\%, respectively, that are faring from the nominated values. The reason may arise from the low vapor pressure of Mn ions. The same result is recorded in ref [40]. Wongsaprom et al. [41] attributed the low Mn doping in $\operatorname{In}_{2} \mathrm{O}_{3}$ to the substitution of In by $\mathrm{Mn}$ ions in the $\operatorname{In}_{2} \mathrm{O}_{3}$ matrix. Berardan et al. [42] found that the maximum solubility limit of $\mathrm{Mn}^{3+}$ ions in $\mathrm{In}_{2} \mathrm{O}_{3}$ do not exceed 7.5 at.\% using sintering process in air. In this regard, when $\mathrm{In}^{+3}$ is replaced by $\mathrm{Mn}^{+2}$ ions, oxygen vacancies are created in case of Mn-1000 and reduced in case of Mn-1030 in terms of temperature increase [32] and the favor of charge neutrality by $\mathrm{Mn}^{+3}$ ions.

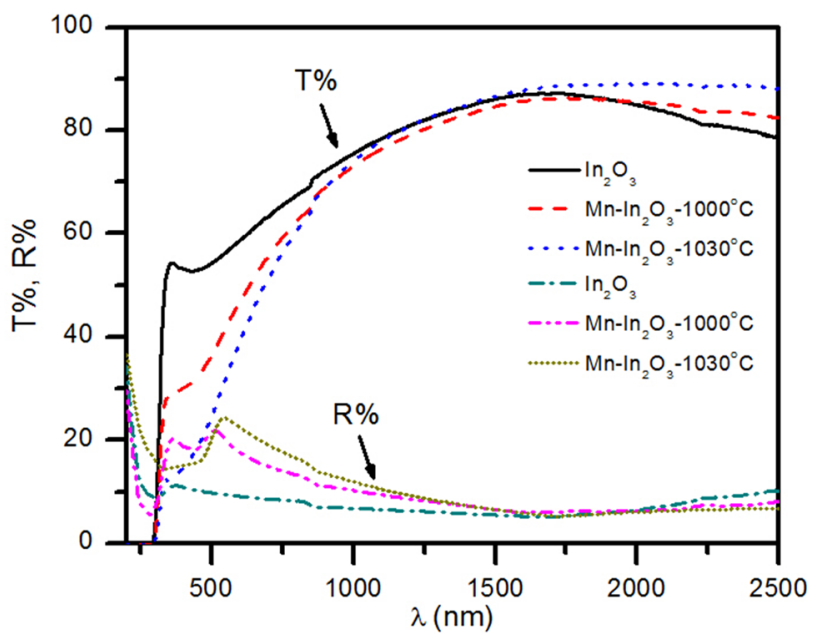

Fig. 4 Transmission and reflection of undoped and $\mathrm{Mn}$ doped $\mathrm{In}_{2} \mathrm{O}_{3}$ films

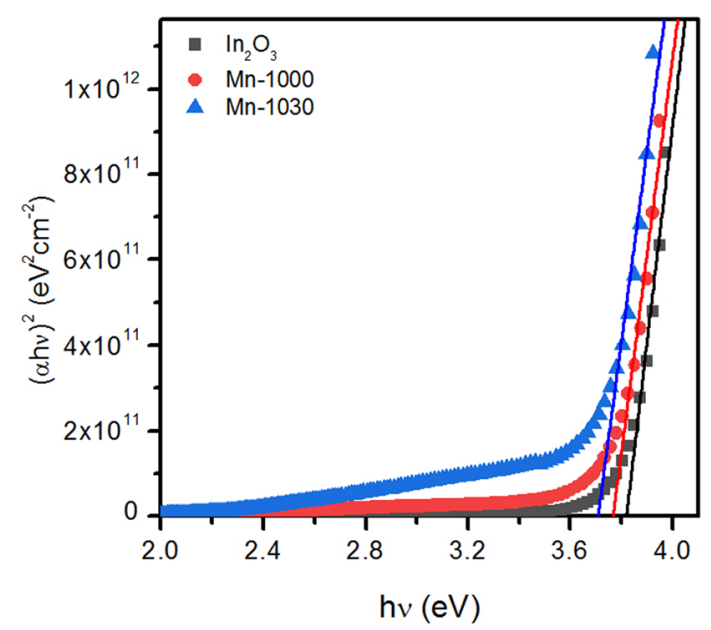

Fig. $5(\alpha h \nu)^{2}$ versus $h \nu$ for undoped and $\mathrm{Mn}$ doped $\mathrm{In}_{2} \mathrm{O}_{3}$ films

\subsection{Optical properties}

The behavior of light when fall on the undoped and Mn doped $\mathrm{In}_{2} \mathrm{O}_{3}$ thin films is depicted in Fig. 4. The transmission of the undoped $\mathrm{In}_{2} \mathrm{O}_{3}$ is not very high as expected which is further reduced in Mn-1000 and Mn-1030. This is mainly originated from light scattering by oxygen vacancies in case of $\mathrm{In}_{2} \mathrm{O}_{3}$ and to phase separation and electronic polarization in cases of Mn-1000 and Mn-1030 [37]. The reflectance exhibits an opposite behavior to transmittance.

The direct band gap $\left(E_{\mathrm{g}}\right)$ are calculated from Tauc formula by taking the relation between $(\alpha h \nu)^{2}$ versus $h \nu$ where the intercepts with energy axis represents $E_{\mathrm{g}}$ values (Fig. 5) [43]. Table 3 summarized the $E_{\mathrm{g}}$ values that are decreased from 3.82 to $3.71 \mathrm{eV}$ with increasing Mn content. Similar results are obtained in refs [19,44-47]. This decrease can 


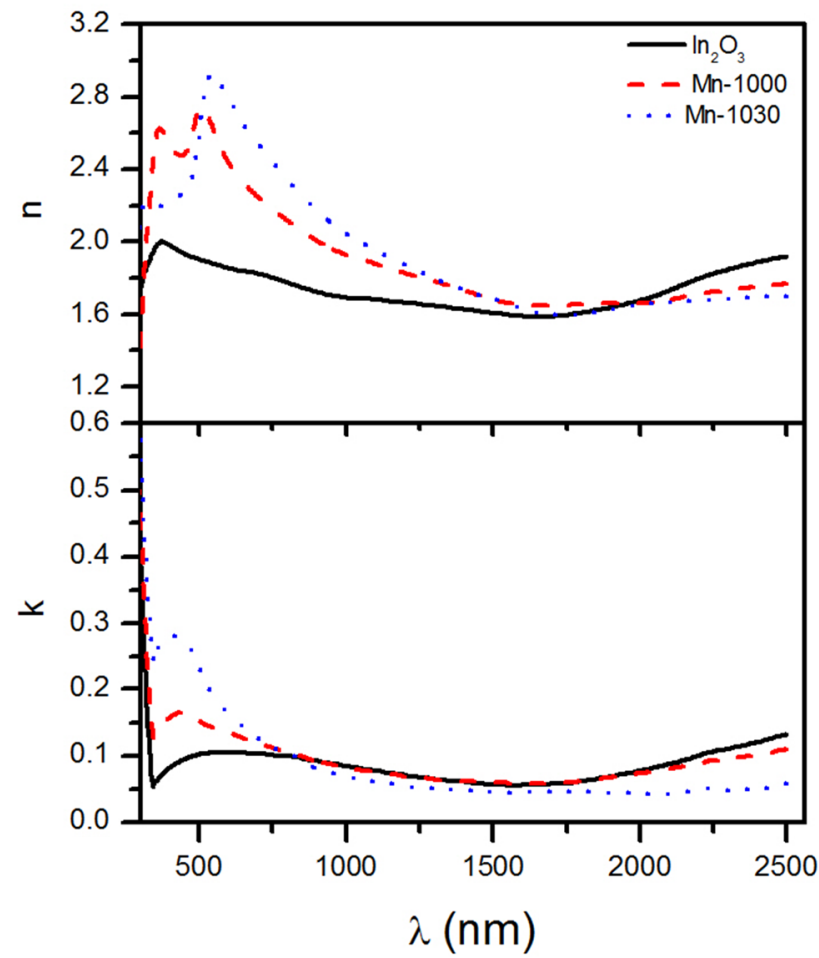

Fig. 6 Refractive index $\mathbf{a}$ and extinction coefficient $\mathbf{b}$ as functions of wavelength for undoped and $\mathrm{Mn}$ doped $\operatorname{In}_{2} \mathrm{O}_{3}$

be ascribed to the SP-D exchange between the localized $\mathrm{d}$-electrons of $\mathrm{Mn}$ cations and the $\mathrm{In}_{2} \mathrm{O}_{3}$ band electrons. This exchange interaction resulted in lowering conduction band and raising the valence band gap edges, therefore shrinking the optical band gap [46].

Figure 6 shows the changes in refractive index $(n)$ with wavelengths that show anomalous dispersion in UV region and normal dispersion in visible and near IR region. The undoped $\operatorname{In}_{2} \mathrm{O}_{3}$ shows $\mathrm{n}$ values smaller than its counterpart using flux method [48]. The reason may arise form oxygen deficient as indicated in EDAX results [49]. The increase in refractive index for the doped thin films arise from the high density of Mn $\left(7.43 \mathrm{~g} / \mathrm{cm}^{3}\right)$ compared to that of In $(7.31 \mathrm{~g} /$ $\mathrm{cm}^{3}$ ). The extinction coefficient $(k)$ of Mn-1000 and Mn-1030 shows steeper shoulder around $400 \mathrm{~nm}$ that is higher than other regions, due to electrons transitions to the impurity levels [50]. The opposite is observed in the undoped $\operatorname{In}_{2} \mathrm{O}_{3}$ with slight shift toward shorter wavelengths. Generally, various defects in the structure promotes different absorption types at different wavelengths besides the fundamental one.

\subsection{Magnetic behavior}

The magnetic response of undoped and $\mathrm{Mn}$ doped $\mathrm{In}_{2} \mathrm{O}_{3}$ at room temperature is depicted in Fig. 7a-c. Although diamagnetic behavior is observed in undoped $\operatorname{In}_{2} \mathrm{O}_{3}$

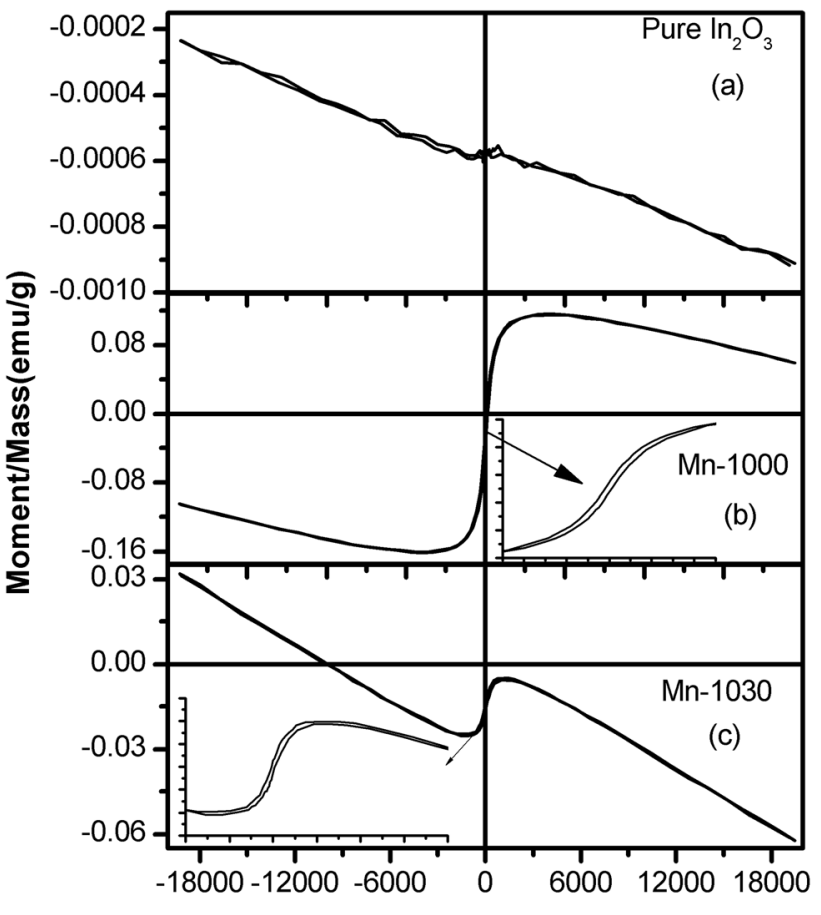

Field (G)

Fig. 7 The magnetic behavior at room temperature of undoped and $\mathrm{Mn}$ doped $\mathrm{In}_{2} \mathrm{O}_{3}$

[33] hysteresis loops are created in case of $\mathrm{Mn}-1000$ and $\mathrm{Mn}-1030$ at low magnetic field $(H=116.75 \mathrm{G})$. The reduction in saturation magnetization $\left(M_{\mathrm{s}}\right)$ of $\mathrm{Mn}-1030$ $(0.006 \mathrm{emu} / \mathrm{g})$ compared with Mn-1000 (0.14 emu/g) indicates that secondary phase in Mn-1030 is not responsible for inducing the room temperature ferromagnetism. The responsible is the trapped electrons by oxygen vacancies that are spin oriented under the application of magnetic field [1]. In Mn-1000 the spin orientations are in the same direction, while in Mn-1030 the tilt present in hysteresis loop with prominent decrease in saturation magnetization may arise from spiral domain wall movement clockwise and counterclockwise due to different $\mathrm{Mn}$ ions that are spun oppositely [51]. It is worth noting that the values of $\mathrm{M}_{\mathrm{s}}$ obtained in Mn-1000 are greater than those values obtained by Zong et al. [21]. The disparity of coercivity and retentivity values of Mn-1000 $\left(33.09 \mathrm{G}\right.$ and $\left.8.99 \times 10^{-3} \mathrm{emu} / \mathrm{g}\right)$ compared with $\left(43.12 \mathrm{G}\right.$ and $\left.1.2 \times 10^{-3} \mathrm{emu} / \mathrm{g}\right)$ of Mn-1030 ensures the differences in their structures and morphologies. Although Mn-1030 has the lowest dislocation density, see Table 2, the anisotropic structure by phase separation represents an obstacle for domain walls movement and this is not recommended in practical applications. On the other hand, the higher retentivity and the lower coercivity of Mn-1000 are related to their homogenous structure and morphology 
that facilitate the domain wall movement hence inducing their beneficial as soft ferromagnetism [51, 52]. Small coercive is beneficial for pulse transformer in the construction of its core [52].

\section{Conclusion}

Diluted magnetic semiconductors have been successfully prepared using CVD technique. The various analyses showed that although Mn doping has slight impact on the crystal structure, it has a significant effect on the magnetic, optical and morphological properties. The $E_{\mathrm{g}}$ values decreased from 3.82 to $3.71 \mathrm{eV}$ with increasing Mn content. The $n$ values, between 200 and $2000 \mathrm{~nm}$, increased with increasing $\mathrm{Mn}$ content. The behavior of hysteresis loop and EDAX analysis was tabulated the optimal temperature and $\mathrm{Mn}$ content for inducing the room temperature ferromagnetisms to be $1000{ }^{\circ} \mathrm{C}$ and 4.23 at.\%, respectively. The higher retentivity and the lower coercivity of Mn-1000 allow their use in pulse transformer.

Funding Open access funding provided by The Science, Technology \& Innovation Funding Authority (STDF) in cooperation with The Egyptian Knowledge Bank (EKB).

\section{Declarations}

Conflict of interest The authors declare that there are no conflict of interest either personally or financially.

Open Access This article is licensed under a Creative Commons Attribution 4.0 International License, which permits use, sharing, adaptation, distribution and reproduction in any medium or format, as long as you give appropriate credit to the original author(s) and the source, provide a link to the Creative Commons licence, and indicate if changes were made. The images or other third party material in this article are included in the article's Creative Commons licence, unless indicated otherwise in a credit line to the material. If material is not included in the article's Creative Commons licence and your intended use is not permitted by statutory regulation or exceeds the permitted use, you will need to obtain permission directly from the copyright holder. To view a copy of this licence, visit http://creativecommons.org/licenses/by/4.0/.

\section{References}

1. H. Kumagai, Y. Hara, K. Sato, J. Magn. Magn. Mater. 489, 165358 (2019)

2. T. Yu-Feng, H. Shu-Jun, Y. Shi-Shen, M. Liang-Mo, Chin. Phys. B 22, 088505 (2013)

3. J. Liu, Ceram. Int. 48, 3390-3396 (2022)

4. S.K. Mandal, A.K. Das, T.K. Nath, Appl. Phys. Lett. 89, 144105 (2006)

5. Y. Li, L. Sun, H. Liu, Y. Wang, Z. Liu, Catalysts 10, 1305 (2020)

6. M. Fraga, R. Pessoa, Micromachines 11, 799 (2020)
7. S.H. Mohamed, M.T. Khan, A. Almohammedi, M.A. Awad, Mater. Sci. Semicond. Process. 123, 105573 (2021)

8. N.M.A. Hadia, M. Alzaid, W.S. Mohamed, Mater. Charact. 165, $110392(2020)$

9. N.M.A. Hadia, W.S. Mohamed, M.S. Abd El-sadek, Mater. Chem. Phys. 235, 121750 (2019)

10. K.C. Verma, R. Bhatia, S. Kumar, R.K. Kotnala, Mater. Res. Express 3, 076103-076114 (2016)

11. S.L. Ou, H.R. Liu, S.Y. Wang, D.S. Wuu, J. Alloy. Compd. 663, 107-115 (2016)

12. A.K. Das, A. Srinivasan, J. Mater. Sci. Mater. Electron. 3, 83838388 (2017)

13. K. Sato, H.K. Yoshida, Phys. Status Solidi B 229, 673-680 (2002)

14. H.K. Yoshida, K. Sato, T. Fukushima, M. Toyoda, H. Kizaki, V.A. Dinh, P.H. Dederichs, Phys. Status Solidi A 204, 15-32 (2007)

15. M.V. Limaye, S.B. Singh, R. Das, P. Poddar, S.K. Kulkarni, J. Solid State Chem. 184, 391-400 (2011)

16. A.K. Rana, Y. Kumar, P. Rajput, S.N. Jha, D. Bhattacharyyaand, P.M. Shirage, ACS Appl. Mater. Interface 9, 7691-7700 (2017)

17. J.E. Ghoul, M. Kraini, L.E. Mir, J. Mater. Sci. Mater. Electron. 26, 2555-2562 (2015)

18. F. Yang, J. Ma, X.J. Feng, L. Y. Kong, J. Cryst. Growth 310, 4054 4057 (2008)

19. A. Karn, N. Kumar, S. Aravindan, J. Nanostruct. 7, 64-76 (2017)

20. Q. Hou, J. Buckeridge, T. Lazauskas, D. Mora-Fonz, A.A. Sokol, S.M. Woodley, C.R.A. Catlow, J. Mater. Chem. C 6, 12386 (2018)

21. Y. Zong, Y. Sun, S. Meng, Y. Wang, H. Xing, X. Li, X. Zheng, RSC Adv. 9, 23012 (2019)

22. A.A.T. Apostolov, I.N. Apostolova, J.M. Wesselinowa, J. Magn. Magn. Mater. 456, 263-268 (2018)

23. S. Wang, Y. An, L. Duan, H. Liu, J. Liu, J. Vac. Sci. Technol. A 31, 061515 (2013)

24. T. Okazaki, T. Yoshioka, Y. Kusakabe, T. Yamamoto, A. Kitada, Solid State Commun. 151, 1749-1752 (2011)

25. S.H. Babu, S. Kaleemulla, N.M. Rao, C. Krishnamoorthi, J. Magn. Magn. Mater. 416, 66-74 (2016)

26. K. Anand, J. Kaur, R.C. Singh, R. Thangaraj, Ceram. Int. 42, 10957-10966 (2016)

27. X. Sun, X. Fu, T. You, Q. Zhang, L. Xu, X. Zhou, H. Yuan, K. Liu, Electron. Mater. Lett. 14, 733-738 (2018)

28. M.M. Amiri, F. Amiri, F. Foroutan, H.A.R. Aliabad, Bulg. Chem. Commun. 50, 335-340 (2018)

29. M.A. Awad, S.H. Mohamed, S.A. Mohamed, Appl. Phys. A 127, $343(2021)$

30. S.H. Mohamed, Z.H. Dughaish, Philos. Mag. 92, 1212 (2012)

31. A. Cremades, M. Herrera, J. Bartolomé, G.C. Vásquez, D. Maestre, J. Piqueras, Phys. B 453, 92-99 (2014)

32. M. Herrera, A. Cremades, D. Maestre, J. Piqueras, Acta Mater. 75, 51-59 (2014)

33. C.S. Barrett, T.B. Massalski, Structures of Metals (Pergamon, Oxford, 1980), p. 204

34. D. Maestre, I. de Mart1́nezVelasco, A. Cremades, M. Amati, J. Piqueras, J. Phys. Chem. C 114, 11748-11752 (2010)

35. C.C. Evan, in Whisker Mill \& Boon (London, 1972), Chap. 2, p. 18

36. Z.R. Dai, Z.W. Pan, Z.L. Wang, Adv. Funct. Mater. 13, 9 (2003)

37. M.A. Awad, E.M.M. Ibrahim, A.M. Ahmed, Eur. Phys. J. Appl. Phys. 72, 30303 (2015)

38. S.H. Mohamed, Philos. Mag. 91, 3598-3612 (2011)

39. T. Tomita, K. Yamashita, Y. Hayafuji, H. Adachi, Appl. Phys. Lett. 87, 051911 (2005)

40. A.B. Djurisic, K.H. Tam, Y.F. Hsu, S.L. Zhang, M.H. Xie, W.K. Chan, Thin Solid Films 516, 238 (2007)

41. K. Wongsaprom, R. Jareanboon, S. Kingcha, S. Pinitsoontorn, W. Ponhan, J. Supercond. Nov. Magn. 30, 1053-1060 (2017) 
42. D. Berardan, E. Guilmeau, D. Pelloquin, J. Mag. Mag. Mater. 320, 983-989 (2008)

43. J. Tauc, R. Grigorovici, A. Vancu, Phys. Status Solidi B 15, $627-$ 637 (1966)

44. S. Wang, Y. An, L. Duan, H. Liu, J. Liu, Z. Wu, J. Vac. Sci. Technol. A 31, 061515 (2013)

45. S.H. Mohamed, J. Korean Phys. Soc. 62, 902-905 (2013)

46. X.L. Wang, C.Y. Luan, Q. Shao, A. Pruna, C.W. Leung, R. Lortz, J.A. Zapien, A. Ruotolo, Appl. Phys. Lett. 102, 102112 (2013)

47. X. Liu, S. Zhang, Z. Wu, Y. An, Superlattice Microstruct. 132, 106174 (2019)

48. O. Medenbach, T. Siritanon, M.A. Subramanian, R.D. Shannon, R.X. Fischer, G.R. Rossman, Mater. Res. Bull. 48, 2240-2243 (2013)

49. M.S. Alqahtani, N.M.A. Hadia, S.H. Mohamed, Optik 145, $377-$ 386 (2017)
50. G.C. Xie, L. Fang, L.P. Peng, G.B. Liu, H.B. Ruan, F. Wu, C.Y. Kong, Phys. Procedia 32, 651-657 (2012)

51. K.B. Ruan, H.W. Ho, R.A. Khan, P. Rena, W.D. Song, A.C.H. Huan, L. Wang, Solid State Commun. 150, 2158 (2010)

52. C.K. Banerjee, in Electrical and Electronics Engineering Material. ed. by A.K. Ghosh (PHI Learning Private Limited, Delhi, 2015)

Publisher's Note Springer Nature remains neutral with regard to jurisdictional claims in published maps and institutional affiliations. 